\title{
Working in swine-confinement buildings causes an accelerated decline in FEV1: a 7-yr follow-up of Danish farmers
}

\author{
M. Iversen, R. Dahl
}

Working in swine-confinement buildings causes an accelerated decline in FEV1: a sevenyear follow-up of Danish farmers. M. Iversen, R. Dahl. C ERS Journals Ltd 2000.

ABSTRACT: Work in swine confinement units causes exposure to high levels of organic dust and is associated with a high prevalence of work-related respiratory symptoms and probably with accelerated decline in forced expiratory volume in one second (FEV1).

A 7-yr follow-up on FEV1, forced vital capacity (FVC), bronchial reactivity, and respiratory symptoms was performed on 181 Danish farmers. The participation rate was $\mathbf{7 6 . 3 \%}$ and nonparticipants had more symptoms, were more likely to be current-smokers and had lower lung function in the first survey than participants in both surveys.

Farmers who worked exclusively with pigs in the follow-up had an accelerated decline in FEV1 but not in FVC compared with dairy farmers, where the observed decline in FEV1 was close to the expected. For a nonsmoking pig farmer compared to a nonsmoking dairy farmer the mean additional decline in FEV1 was $17 \mathrm{~mL} \cdot \mathrm{yr}^{-1}(53.0$ $\mathrm{mL} \cdot \mathrm{yr}^{-1}$ versus $\left.36.1 \mathrm{~mL} \cdot \mathrm{yr}^{-1}\right)$.

The authors conclude that working in swine confinement units causes an accelerated decline in forced expiratory volume in one second but not in forced vital capacity. The mean decline is $\sim 0.5 \mathrm{~L}$ during a working life and some farmers will develop clinically significant airway obstruction due to work in swine confinement units. Eur Respir J 2000; 16: 404-408.
Dept of Respiratory Diseases, University Hospital of Aarhus, Denmark.

Correspondence: M. Iversen, Lungemedicinsk afdeling, Aarhus Kommunehospital, Norrebrogade 44, 8000 Aarhus C, Denmark. Fax 4589492090

Keywords: Airway obstruction bronchial reactivity

dust

farming

Received: January 122000

Accepted after revision May 292000

The study was supported by a grant from Danmark Lungeforening.
Working in closed swine-confinement buildings is always associated with exposure to high concentrations of organic dust [1] and high prevalence of work-related respiratory symptoms in cross-sectional studies. This has been confirmed in several studies from northern Europe, Canada, and the USA [2-8]. The dust from confinement buildings has strong biological properties and causes severe bronchial inflammation $[9,10]$ and work in confinement buildings is associated with a cross-shift decline in forced expiratory volume in one second (FEV1) [7, 11, 12]. Several cross-sectional studies have suggested that pig farmers develop bronchial hyperresponsiveness and that this is related to symptoms and airway obstruction $[8$, 13-16]. Results from cross-sectional studies [8, 13] have suggested that work in swine confinement buildings is associated with and accelerated decline in FEV1 and this seems to be confirmed from longitudinal studies [14-17].

The purpose of this longitudinal study was to investigate whether farmers with exclusively swine farming (high dust exposure) had an accelerated decline in FEV1 compared to farmers with exclusively dairy farming (low dust exposure) a longitudinal study. Secondary endpoints were development in respiratory work-related symptoms and bronchial reactivity and its relation to decline in FEV1.

\section{Methods}

From a previous cross-sectional study [8] all 181 male farmers were invited to a 7-yr follow-up. Measurement of
FEV1/forced vital capacity (FVC) and bronchial reactivity by histamine challenge was performed with the same equipment and with the same procedure as in the first survey [8]. The group of farmers consisted of full-time farmers with medium to large farms who were exclusively pig or dairy farmers at the first survey.

\section{Questionnaire}

Farmers were asked about their farming practices and smoking habits in the follow-up period so that they could be classified according to exposure. Furthermore, they were asked about the presence of work-related respiratory symptoms like shortness of breath, wheezing and dry cough when working in the confinement building. The questions on respiratory symptoms were the same as in the first survey.

\section{Lung function measurements}

A dry bellow spirometer, Vitalograph S-20600 (Vitalograph Ltd., Buckingham, UK) was used for measurement of FEV1 and FVC. Before the study period the spirometer was calibrated by a certified technician to an accuracy of within $1 \%$. The spirometer was checked each study day for leaks by a calibrated syringe. Persons were in the standing position and no nose clip was used. FEV1 and FVC was determined according to the same guidelines as in the first 
survey. After two or more practice blows FEV1 and FVC was determined as the highest value from the results of measurements.

\section{Histamine challenge}

Bronchial reactivity to histamine was performed in accordance with a method described by CocKROFT et al. [18]. The aerosol was generated by a Wright nebulizer, calibrated to give a constant output of $0.13-0.15 \mathrm{~mL} \cdot \mathrm{min}^{-1}$. The aerosol was inhaled during 2 min of tidal breathing through a mouthpiece. A nose clip was used. FEV1 was measured before start of the procedure and $90 \mathrm{~s}$ after each inhalation (Vitalograph, Model S; Vitalograph Ltd.). FEV1 after isotonic saline inhalation was used as baseline. Histamine dihydrochloride was inhaled in doubling concentrations from $0.03-32 \mathrm{mg} \cdot \mathrm{mL}^{-1}$. The results were expressed as the provocative concentration of histamine causing a $20 \%$ fall in FEV1 (PC20) histamine obtained from the log dose-response curve by linear interpolation of the two last points or the slope calculated as the maximal fall in per cent of FEV1 divided by the cumulative doses of histamine in $\mathrm{mg}$. Bronchial hyperreactivity in this study means a PC20 histamine of $\leq 32 \mathrm{mg} \cdot \mathrm{mL}^{-1}$.

\section{Statistics}

Parametric statistics were used with the Statistical Package for the Social Sciences (SPSS) [19]. Analysis of variance with covariate analysis was used to compare means and multiple linear regression analysis to study explanatory variables for decline in FEV1 and FVC. Test for normal distribution of variables was performed with the Lilliefors test. A significance level of 0.05 was used throughout. Because of a very skewed distribution of bronchial reactivity, measurements were compared with nonparametric statistics, Wilcoxon matched pairs test for paired comparison and Mann-Whitney Wilcoxon test for unpaired comparisons.

\section{Results}

\section{Participants versus nonparticipants}

Of the 181 farmers, four died in the follow-up period. Death certificates were obtained from the national death certificate register. None of the deaths were caused by respiratory disease and the four deceased farmers had lung function values in the normal range at the survey in 1989. Of 177 farmers, $135(76.3 \%)$ participated in the survey. Participants and nonparticipants were of the same age and height and had the same number of working hours in confinement buildings (table 1) but nonparticipants had significantly lower FEV1 (96.0\% versus $105.3 \%)$, FVC, $\mathrm{FEV} 1 / \mathrm{FVC}$ ratio and more respiratory symptoms during work $(39.1 \%$ versus $24.4 \%)$ and more were smokers $20.7 \%$ versus $34.8 \%$ ) than participants (table 1 ). The daily number of working hours in the confinement buildings were nearly the same in participants and nonparticipants $(5.0$ and $5.3 \mathrm{~h})$. Three farmers had changed their farming practices so that they could not be classified as
Table 1. - Personal characteristics of participants and nonparticipants in follow-up study

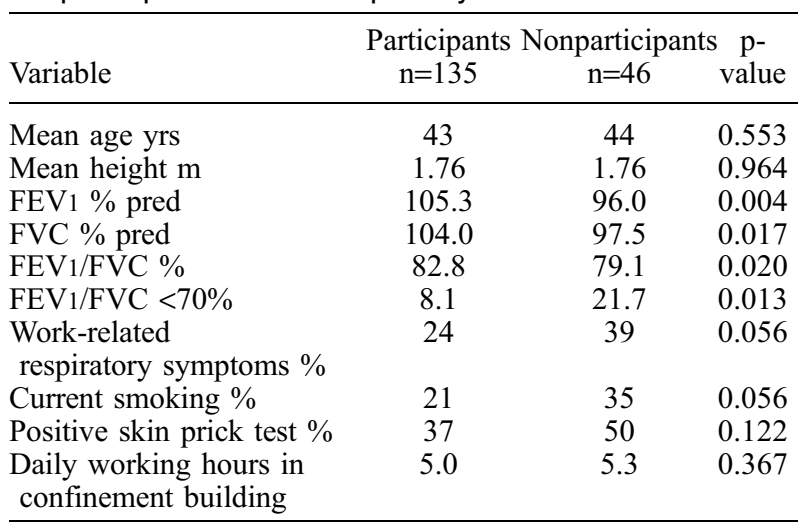

FEV1: forced expiratory volume in one second; FVC: forced vital capacity; \% pred: percentage of the predicted value.

exclusively pig or dairy farmers in the follow-up period, therefore 132 farmers were included in the analysis.

Decline of forced expiratory volume in one second and forced vital capacity

The decline of FEV1 (fig. 1), and FVC (fig. 2), showed a continuous distribution not significantly different from a normal distribution $(\mathrm{p}>0.20)$. This also applied to the subgroups of dairy farmers/swine farmers and smokers/ nonsmokers with a normal distribution (Lilliefors test, $\mathrm{p}>0.05)$.

Because the first cross-sectional survey had demonstrated an interaction between smoking and pig farming, the decline in FEV1 and FVC were analysed separately in farmers who were nonsmokers in the study period and in the whole group of farmers.

Corrected for age, height and pack-yrs in the study period the annual decline in FEV1 of pig farmers was significantly higher than dairy farmers (53.8 versus $41.8 \mathrm{~mL}$, $\mathrm{p}=0.045)$, whereas there was no significant difference for FVC (33.7 versus $39.1 \mathrm{~mL}, \mathrm{p}=0.608$ ) (table 2 ). With the analysis restricted to farmers who were nonsmokers in the

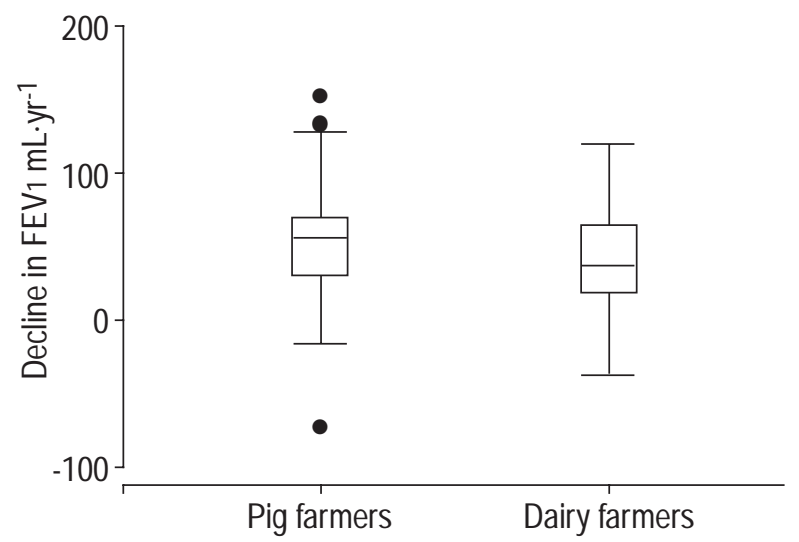

Fig. 1. - Box-plot of decline in forced expiratory volume in one second $(\mathrm{FEV} 1)\left(\mathrm{mL} \cdot \mathrm{yr}^{-1}\right)$ in pig and dairy farmers. Fifty per cent of observations are within the closed boxes, median values are indicated by the solid lines. outliers. 


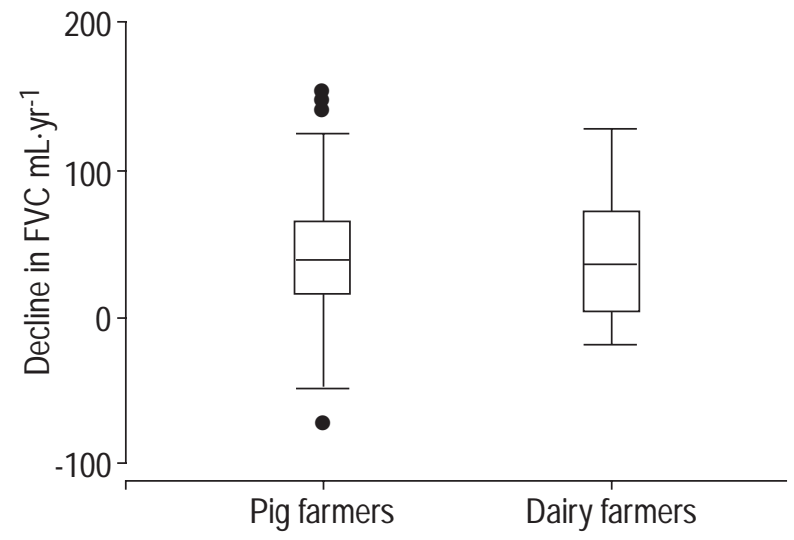

Fig. 2. - Box-plot of decline in forced vital capacity $(\mathrm{FVC})\left(\mathrm{mL} \cdot \mathrm{yr}^{-1}\right)$ in pig and dairy farmers. Fifty per cent of observations are within the closed boxes, median values are indicated by the solid lines. 0 : outliers.

study period, the difference was more pronounced for FEV1 $\left(53.0 \mathrm{~mL} \cdot \mathrm{yr}^{-1}\right.$ for pig farmers and $36.1 \mathrm{~mL} \cdot \mathrm{yr}^{-1}$ for dairy farmers $(\mathrm{p}=0.018))$ whereas $\mathrm{FVC}$ was essentially unchanged (38.2 $\mathrm{mL} \cdot \mathrm{yr}^{-1}$ versus $\left.36.8 \mathrm{~mL} \cdot \mathrm{yr}^{-1}, \mathrm{p}=0.920\right)$ (table 3).

Multiple linear regression analysis showed that the level of bronchial reactivity expressed by the histamine slope at the initial survey was not a significant predictor for decline in FEV1 in the total group $(p=0.536)$ (table 4), or in the group of nonsmokers $(\mathrm{p}=0.340)$ (table 5$)$.

\section{Bronchial reactivity}

In the first survey bronchial reactivity was not significantly different between pig and dairy farmers $(p=0.715)$ nor was it in the second survey $(\mathrm{p}=0.969)$. With linear correction for FEV1 with respect to $\mathrm{PC} 20$ histamine a significant, although small, decrease in bronchial hyperreactivity was seen ( $p>0.001$ for pig and dairy farmers). The difference in both groups was caused by a number of persons going from light bronchial hyperreponsiveness to a nonrespondent status (fig. 3).

\section{Work-related respiratory symptoms}

The number of persons with asthma-like respiratory symptoms like wheezing, shortness of breath or dry cough during work in the animal house was similar in the two surveys $(n=11)$ and they were all found among the pig farmers.

Table 2. - Values of decline in forced expiratory volume in one second (FEV1) and forced vital capacity (FVC) for pig and dairy farmers. Analysis of variance with correction for age, height, and pack-yrs in the follow-up period

\begin{tabular}{lccc}
\hline Variable & $\begin{array}{c}\text { Pig farmers } \\
\mathrm{n}=94\end{array}$ & $\begin{array}{c}\text { Dairy farmers } \\
\mathrm{n}=38\end{array}$ & p-value \\
\hline Decline in FEV1 & 53.8 & 41.8 & 0.045 \\
Decline in FVC & 33.7 & 39.1 & 0.608 \\
\hline
\end{tabular}

Data presented as $\mathrm{mL} \cdot \mathrm{yr}^{-1}$.
Table 3. - Values of decline in forced expiratory volume in one second (FEV 1 ) and forced vital capacity (FVC) for pig and dairy farmers who did not smoke in the follow-up period. Analysis of variance with correction for age and height

\begin{tabular}{lccc}
\hline Variable & $\begin{array}{c}\text { Pig farmers } \\
\mathrm{n}=76\end{array}$ & $\begin{array}{c}\text { Dairy farmers } \\
\mathrm{n}=26\end{array}$ & $\mathrm{p}$-value \\
\hline Decline in FEV1 & 53.0 & 36.1 & 0.018 \\
Decline in FVC & 38.2 & 36.8 & 0.920 \\
\hline
\end{tabular}

Data presented as $\mathrm{mL} \cdot \mathrm{yr}^{-1}$.

Pig farmers with symptoms had more airways obstruction than nonsymptomatic pig farmers $(\mathrm{FEV} 1 / \mathrm{FVC}$ ratio 0.76 versus $0.84, \mathrm{p}=0.316$ ) larger annual decline in $\mathrm{FEV} 1$ (72.7 versus $51.7 \mathrm{~mL}, \mathrm{p}=0.066$ ), larger annual decline in FVC (58.2 versus $30.34 \mathrm{~mL})$ and there were more current smokers $(36 \%$ versus $13 \%, p=0.123)$ but none of the differences were significant.

\section{Discussion}

This 7-yr follow-up study had a bias in the participation as nonparticipants had significantly more work-related respiratory symptoms, airways obstruction and number of current-smokers. However there was no bias with respect to pig/dairy farmer, age, height or number of working hours in confinement building. The bias is substantial and probably means that this study will underestimate the harmful effects of pig farming with respect to decline in FEV1.

Participation in the first survey and knowing the results of lung function measurements represents another possible bias. Pig farmers especially had increased awareness of the potential harmful effects of their occupation and the harmful effects of smoking and some took measures to reduce exposure. This bias, which would tend to diminish the effects of pig farming found in this study were not evaluated. Nonsmoking dairy farmers had an annual decline in FEV1 very close to the expected $30 \mathrm{~mL} \cdot \mathrm{yr}^{-1}$ found nonsmoking Danish men in a non rural population [20]. The excess decline due to pig farming had a mean value of $17 \mathrm{~mL} \cdot \mathrm{yr}^{-1}$ which would correspond to $0.51 \mathrm{~L}$ in $30 \mathrm{yrs}$ of work. As the normal physiological loss of FEV1 from the age of 30 to the age of 60 is $\sim 1 \mathrm{~L}$ an additional decline of $0.5 \mathrm{~L}$ represents a substantial loss. Farmers with FEV1 values low in the normal range or higher than average decline in FEV1 due to pig farming will probably develop clinically significant airways obstruction before the age of

Table 4. - Regression analysis of decline in forced expiratory volume in one second (FEV1), results from all 132 participants

\begin{tabular}{lccc}
\hline & \multicolumn{3}{c}{$\begin{array}{c}\text { Dependent variable: decline } \\
\text { in FEV1 } \mathrm{mL} \cdot \mathrm{yr}^{-1}\end{array}$} \\
\cline { 2 - 4 } Predictor variable & $\mathrm{B}$ & $\mathrm{SE}$ of B & $\mathrm{p}$-value \\
\hline Histamine slope 1989 & 0.057 & 0.097 & 0.536 \\
Pig versus dairy farming & -11.010 & 6.328 & 0.084 \\
Smoking in follow-up & 2.421 & 6.535 & 0.711 \\
Constant 61.521 & & & \\
\hline
\end{tabular}

B: regression coefficient; SE: standard error. 
Table 5. - Regression analysis of decline in forced expiratory volume in one second (FEV 1$)$, results from the 101 participants who were nonsmokers in the followup period

\begin{tabular}{lccc}
\hline & \multicolumn{3}{c}{$\begin{array}{c}\text { Dependent variable: decline } \\
\text { in FEV1 } \mathrm{mL} \cdot \mathrm{yr}^{-1}\end{array}$} \\
\cline { 2 - 4 } Predictor variable & $\mathrm{B}$ & $\mathrm{SE}$ of B & $\mathrm{p}$-value \\
\hline Histamine slope 1989 & 0.452 & 0.103 & 0.340 \\
Pig versus dairy farming & -15.205 & 7.161 & 0.036 \\
FEV1 in 1989 L & 0.009 & 0.042 & 0.843 \\
Constant 64.349 & & & \\
\hline
\end{tabular}

B: regression coefficient; SE: standard error.

sixty. Smoking in pig farmers would aggravate this further.

The excess decline in FEV1 found in this study is comparable, although lower, to the results from studies from Canada [21] and the Netherlands [22] where there was a mean decline of $26 \mathrm{~mL} \cdot \mathrm{yr}^{-1}$ and $10-70 \mathrm{~mL} \cdot \mathrm{yr}^{-1}$ depending on endotoxin exposure. In contrast with the Canadian and Dutch studies, an excess decrease in FVC was not found, thus extending the results from previous cross-sectional surveys $[8,13]$ and longitudinal survey [17] where development of airways obstruction was found. In the first survey [8] there was evidence of airways obstruction in pig farmers compared to dairy farmers but there was no evidence of impairment in diffusion capacity. This is also in accordance with the study with transbronchial biopsies performed by SchwARTz et al. [23] from Iowa, where no evidence of parenchymal damage was seen and with the longitudinal study from the same centre [24].

Contrary to what was to be expected from previous cross-sectional surveys $[8,13]$ a general increase in bronchial reactivity in pig farmers during the follow-up period was not seen nor was any increase in the number of

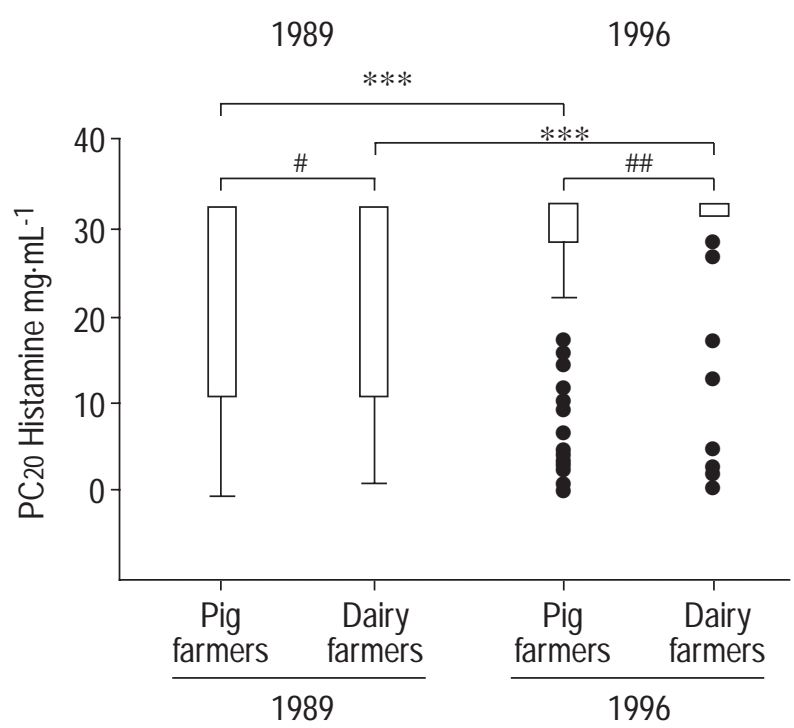

Fig. 3. - Box-plot of decline in provocative concentration of histamin causing a $20 \%$ fall in forced expiratory volume in one second (PC20 histamine) in 1989 and 1996 in pig and dairy farmers. Fifty per cent of observations are within the closed boxes, median values are indicated by the solid lines. : outliers; $* * *: p=0.001 ;{ }^{\#}: \mathrm{p}=0.715 ;{ }^{\# \#}: \mathrm{p}=0.969$. persons with work-related respiratory symptoms. This could be due to selection bias in the participation since nonparticipants were more affected than participants and possibly to declining exposure in the follow-up period, because many farmers became aware of the risk and some changed their working practices.

In conclusion, nonsmoking pig farmers experience significant excess decline in forced expiratory volume in one second but not in forced vital capacity over a 7-yr period, whereas nonsmoking dairy farmers have declines in forced expiratory volume in one second and forced vital capacity comparable to the general population.

\begin{abstract}
Acknowledgements. The authors wish to thank senior research nurse G. Fløe for excellent work during the study.
\end{abstract}

\section{References}

1. Donham KJ. Health effects from work in swine confinement buildings. Am J Ind Med 1990; 17: 17-25.

2. Donham KJ, Zavala DC, Merchant JA. Respiratory symptoms and lung function among workers in swine confinement buildings. Arch Environ Health 1984; 39: 96-101.

3. Iversen M, Dahl R, Korsgaard J, Hallas T, Juel Jensen E. Respiratory symptoms in Danish farmers: an epidemiological study of risk factors. Thorax 1988; 43: 872-877.

4. Dosman JA, Graham BL, Hall DL, et al. Respiratory symptoms and alterations in pulmonary function tests in swine producers in Saskatchewan: results of a survey of farmers. J Occup Med 1988; 30: 715-720.

5. Bongers P, Houthuijs D, Remijn B, Brouwer R, Biersteker K. Lung function and respiratory symptoms in pig farmers. Br J Ind Med 1987; 44: 819-823.

6. Cormier Y, Boulet LP, Bedard G, Tremblay G. Respiratory health of workers exposed to swine confinement buildings only or to both swine confinement buildings and dairy farms. Scand J Work Environ Health 1991; 17 : 269-275.

7. Donham K, Haglind P, Peterson Y, Rylander R, Belin L. Environmental and health studies in farm workers in Swedish swine confinement buildings. $\mathrm{Br} J$ Ind Med 1989; 46: 31-37.

8. Iversen M, Pedersen B. Relation between respiratory symptoms, type of farming, and lung function disorders in farmers. Thorax 1990; 45: 919-923.

9. Larsson KA, Eklund AG, Hansson L-O, Isaksson B-M, Malmberg PO. Swine dust causes intense airways inflammation in healthy subjects. Am J Respir Crit Care Med 1994; 150: 973-977.

10. Pedersen B, Iversen M, Larsen B, Dahl R. Pig farmers have signs of bronchial inflammation with increased number of lymphocytes and neutrophils in BAL fluid. Eur Respir J 1996; 9: 524-530.

11. Donham KJ, Zavala DC, Merchant J. Acute effects of the work environment on pulmonary functions of swine confinement workers. Am J Ind Med 1984; 5: 367-375.

12. Iversen M, Takai H. Lung function studies in farmers during work in swine confinement units. Zbl Arbeitsmed 1990; 40: 236-242. 
13. Iversen M, Dahl R, Jensen EJ, Korsgaard J, Hallas T. Lung function and bronchial reactivity in farmers. Thorax 1989; 44: 645-649.

14. Scheefeldt M, Wilfert A, Lehnick B, Wosnitzka H. Bronchiale Hyperreaktivitat bei Beschaftigter in der Sweineund Rinderproduktion. Z Erkrank Atmorg 1990; 174: 131-136.

15. Zhou C, Hurst TS, Cockcroft DW, Dosman JA. Increased airways responsiveness in swine farmers. Chest 1991; 99: 941-944.

16. Bessette L, Boulet L-P, Tremblay G, Cormier Y. Bronchial responsiveness to metacholine in swine confinement workers. Arch Environ Health 1993; 48: 73-77.

17. Iversen M, Brink O, Dahl R. Lung function in a five-year follow-up study of farmers. Ann Agric Environ Med 1994; 1: 39-43.

18. Cockcroft DW, Killian DN, Mellon JJA, Hargreave FE. Bronchial reactivity to histamine: a method and a survey. Clin Allergy 1977; 7: 235-243.
19. SPSS/PC+ 4.0 Manual, SPSS Inc., Chicago, 1990.

20. Lange P, Groth S, Nyboe J, et al. Decline of the lung function related to the type of tobacco smoked and inhalation. Thorax 1990; 45: 22-26.

21. Senthilselvan A, Dosman JA, Kirychuk P, et al. Accelerated lung function decline in swine confinement workers. Chest 1997; 111: 1733-1741.

22. Vogelzang PFJ, van der Gulden JW, Folgering $\mathrm{H}$, et al. Endotoxin exposure as a major determinant of lung function decline in pig farmers. Am J Respir Crit Care Med 1998; 157: 15-18.

23. Schwartz DA, Landas SK, Lassise DR, Burmeister LF, Hunninghake GW, Merchant JA. Airway injury in swine confinement workers. Ann Intem Med 1992; 116: 630635.

24. Schwartz DA, Donham KJ, Olenchock SA, et al. Determinants of longitudinal changes in spirometric function among swine confinement operaters and farmers. Am J Respir Crit Care Med 1995; 151: 47-53. 